\title{
Mechanical properties of copper processed by Equal Channel Angular Pressing - a review
}

\author{
Ludvík Kunz \\ Institute of Physics of Materials, Academy of Sciences of the Czech Republic, Czech Republic.
}

Luca Collini

Department of Industrial Engineering, University of Parma, Italy.

\begin{abstract}
The Equal Channel Angular Pressing is a hardening treatment with which ductile metals can be processed to refine their grain and sub-grain structure. This process enhances the mechanical strength of metals in terms of tensile strength, stress-controlled fatigue strength, and fatigue crack growth resistance. In this paper the authors draw a review of the major results of a wide research activity they carried out on a copper microstructure processed by Equal Channel Angular Pressing. The essential results are that tensile and fatigue strengths of the so obtained refined structure are improved by a factor of two with respect to the original coarse-grained metal. The fatigue crack initiation mechanism and the stability of the refined microstructure under cyclic loading are topics also discussed, evidencing the essential role of the process and of the material parameter, as the content of impurities in the microstructure. In this review, the authors also underline some critical aspects that have to be more investigated.
\end{abstract}

KEYwORDS. Ultrafine-grain structure; Equal Channel Angular Pressing; Copper; fatigue; fatigue crack resistance.

\section{INTRODUCTION}

$\mathrm{M}$ ankind has used copper since the ancient times. Its mechanical properties and structure are well explored and known. Application of copper in many branches of industry, e.g. in production of wires, copper-based solar power collectors, integrated circuits and generally in electronics, is intensive and has been steadily increasing in recent decades. Copper can be also recycled very effectively and represents a relevant engineering material also for the future.

Copper belongs to the most thoroughly investigated metals. Detailed studies of the relation of mechanical properties and microstructure have been already performed in the second half of the last century [1]. The effort of increasing the mechanical properties of engineering materials, led in the last two decades to the development of the so-called severe plastic deformation (SPD) processes, resulting in fine-grained structures that exhibit improved mechanical properties. $\mathrm{Cu}$ was again a material which was used in the early studies as a model material.

This work briefly summarises the mechanical behaviour of ultrafine-grained (UFG) Cu prepared by one of the SPD methods, namely by Equal Channel Angular Pressing (ECAP). This method enables the production of the UFG Cu in bulk, which is favourable from the industrial point of view. The emphasis in this work is put on the fatigue properties and their relation to the UFG microstructure, even if discussion of recent - and in some cases inconsistent - results on UFG $\mathrm{Cu}$ published in literature, is accentuated. However, also the tensile properties, the relation of the cyclic softening/hardening to the stability of UFG structure, the mechanism of the cyclic slip localization and initiation and propagation of fatigue cracks are the topics reviewed in this work. 


\section{ULTRAFINE-GRAINED COPPER}

$\mathrm{S}$ evere plastic deformation of metallic materials has attracted considerable attention of researchers in material science within the last two decades. The main reason and expectation was to improve the mechanical properties of metals and alloys by substantial grain refinement, which is unavailable by conventional methods. It has been well known for a long time that a fine-grained material exhibits better strength and hardness than that one which is coarse-grained. Reduction of the grain size usually also improves fracture toughness. The physical reason of improved mechanical properties lies in the higher grain boundary volume in fine-grained structures, which makes the dislocation motion and resulting plastic deformation more difficult. For many materials the yield stress follows the Hall-Petch equation in very a broad range of grain size between $1 \mu \mathrm{m}$ and $1 \mathrm{~mm}$ [2]. Deviations from this law are observed only for very coarse grained and for nano-grained structures.

\section{Equal Channel Angular Pressing}

Equal Channel Angular Pressing is the most popular SPD technique. The fundamentals of this procedure, the details of the process and conditions of material flow during pressing can be found in many specialized papers, e.g. [3,4]. The principle of the method is simple. It consists in pressing of a rod-shaped billet through a die with an angular channel having an angle $\phi$, often equal to $90^{\circ}$, Fig. 1.

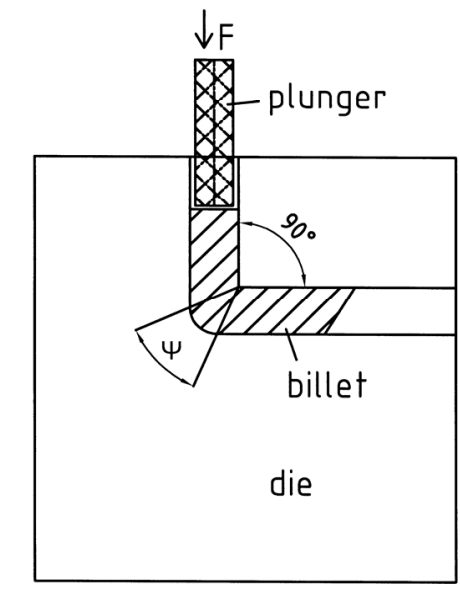

Figure 1: Principle of ECAP procedure

When the billet is pressed by a plunger through the knee of the channel the material of the billet is severely shear strained. Since the cross-sectional dimensions of the billet remain constant after passing the channel, the procedure can be repeated. The final result is the imposition of a very high plastic strain to the processed material. The majority of laboratory ECAP dies has a channel with a quadratic cross-section. The billets can be rotated by increments of 90 degree between particular passes. Indeed, the rotating procedure is feasible also for dies and samples with circular cross-section. Four different ECAP routes are distinguished (Route A, route Ba, route $\mathrm{Bc}$ and route $\mathrm{C}$ ).

The equivalent strain, $\varepsilon$, reached by pressing through a die characterised by outer arc of curvature $\psi$ of the cannels inclined mutually at an angle $\phi$, is given by the relationship [4]:

$$
\varepsilon=(N / \sqrt{3})\{2 \cot [(\phi / 2)+(\psi / 2)]+\psi \operatorname{cosec}[(\phi / 2)+(\psi / 2)]\}
$$

Processing by SPD methods, investigation of the resulting UFG structures and their properties, is a matter of rapidly increasing number of research papers. The current results are regularly presented at the NanoSPD conference series; the last was held in 2011 [5]. A plenty of improvements of ECAP procedure has been proposed in the past. Even though the requirements of process improvements and economically feasible production of UFG materials in sufficient volumes activates development of plenty of SPD methods (like accumulative roll bonding, multiaxial forging or twist extrusions), the majority of basic knowledge on UFG materials is based just on research on materials processed by simple ECAP. This 
holds also for $\mathrm{Cu}$, which was the simple f.c.c. model material used for pioneering studies on fatigue behaviour of UFG structures prepared by SPD $[6,7]$.

\section{ECAPed microstructure of this study}

UFG materials typically exhibit a grain size in the range of hundreds of nanometers. This is a transition region between the coarse grained (CG) materials and nanostructured metals, where the grain boundaries play a decisive role during plastic deformation. The first few ECAP passes result in an effective grain refinement taking place in successive stages: homogeneous dislocation distribution, formation of elongated sub-cells, formation of elongated subgrains and their following break-up into equiaxed units. On the contrary, the microstructure tends to be more equiaxed as the number of passes increases. Later on, the sharpening of grain boundaries and final equiaxed ultrafine grain structure develops.

The microstructure of $\mathrm{Cu}$ prepared by ECAP can vary in many parameters. UFG $\mathrm{Cu}$ produced in different laboratories often slightly differs in the grain size distribution, particularly in grains shape and orientation, in dislocation structure and dislocation arrangement in grain boundaries, and in texture and misorientation between adjacent grains [8,9]. The mutual orientation of structural units cannot be satisfactorily described as high-angle random orientation, because there are regions where low angle boundaries are present, and also regions which can be described as regions of near-by oriented grains. That is why instead of the term "grain size" a term "dislocation cell size" is sometimes used.

UFG structure of $\mathrm{Cu}$ of purity $99.9 \%$ is shown in Fig. 2. Cylindrical billets of $20 \mathrm{~mm}$ in diameter and $120 \mathrm{~mm}$ in length were produced by eight ECAP passes by the route $\mathrm{Bc}$ (i.e. billet rotation by $90^{\circ}$ in the same direction after each consecutive pressing). After the last pass through the die the samples of $16 \mathrm{~mm}$ in diameter and $100 \mathrm{~mm}$ in length were machined from the billets. The severe plastic deformation was conducted at room temperature. The microstructure as observed by transmission electron microscopy (TEM) in the middle of a longitudinal section of the cylindrical sample is shown in Fig. 2a. The structure in transversal direction is shown in Fig. 2b. The average grain size, determined on at least 10 electron micrographs, is $300 \mathrm{~nm}$. This is in full correspondence with other reports on ECAPed pure $\mathrm{Cu}$ that indicate the most frequent grain size of $300 \mathrm{~nm}$, irrespectively to the number of passes applied [10]. The size distribution, however, is getting narrower with increasing number of passes and both total and grain-to-grain misorientation tends to reach high-angle type. Structures with different morphological features can be distinguished according to [11]: the equiaxial structure, referred to as "A", and elongated grain structure called "B". In the course of the ECAP procedure, it is highly possible to obtain a mixture of the type A and B structures. The microstructure in Fig. 2a resembles the type B, and the structure in Fig. $2 \mathrm{~b}$ represents the equiaxial type A.

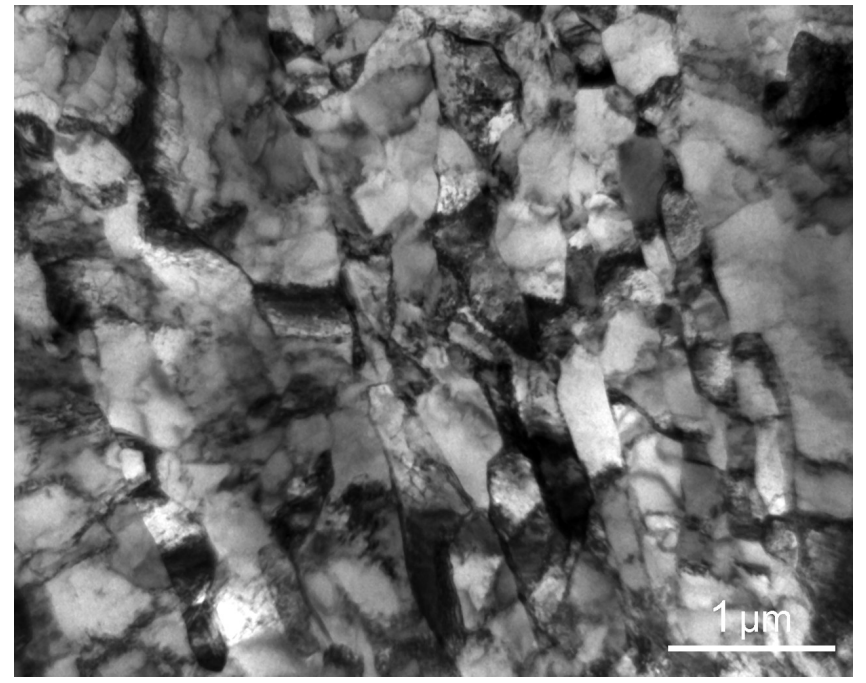

Figure 2a: Microstructure of $\mathrm{Cu}$ after ECAP as observed in TEM, longitudinal section.

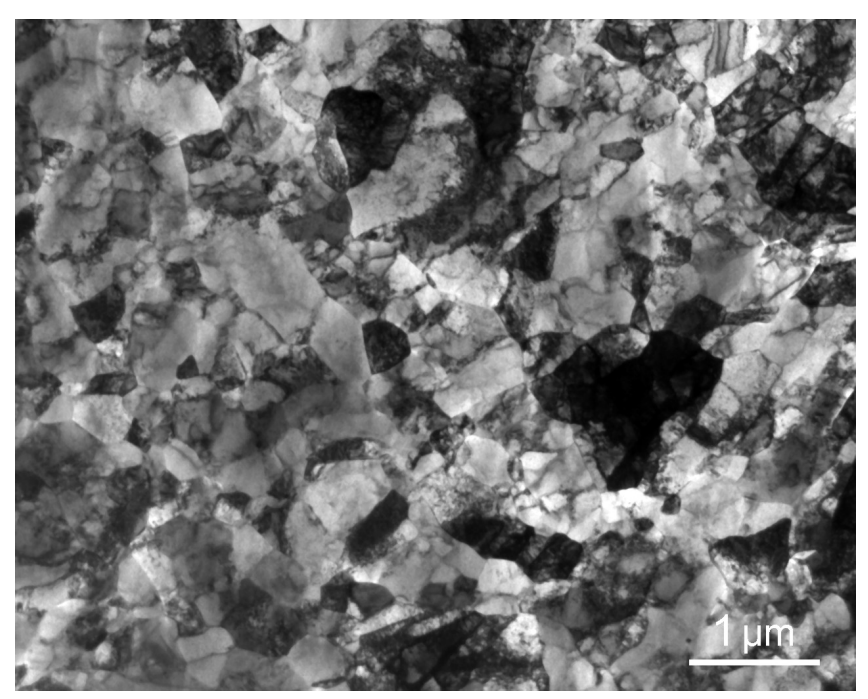

Figure 2b: Microstructure of $\mathrm{Cu}$ after ECAP as observed in TEM, transversal section.

For characterisation of microstructure, electron back scattering diffraction (EBSD) has been recently used beyond the TEM [12]. EBSD analysis is predominantly focused on the experimental determination of misorientation of a crystallographic lattice between adjacent analysed points. This technique, in contrast to TEM of thin foils, enables one to investigate the changes of microstructure in the course of fatigue loading, because the same area of the specimen gauge length can be examined before and after the fatigue loading. An example of a microstructure as observed by EBSD and 
the analysis of EBSD data is shown in Fig. 3. A grain map is shown in Fig. 3a. Grains, defined as areas having the mutual misorientation higher than 1 degree (a threshold angle value, which can be obviously adjusted), are marked by particular colours. Fig. 3b shows the grain size distribution. It can be seen that nearly $50 \%$ of area fraction is composed of grains having an area smaller than $0.5 \mu \mathrm{m}$. Indeed, the direct comparison with the structure displayed by TEM is not possible, because the evaluation procedure of EBSD images is primarily dependent on the adjusted threshold angle. However, for the constant threshold angle the method is very suitable for detection of changes of microstructure and grain orientation due to fatigue loading or temperature exposition.

The UFG structure produced by ECAP is sensitive to the technological details of the process, lubrication, deformation rate, dimensions of the die, etc. With no doubt, these factors influence the microstructure and finally the properties of UFG material. So, the diversity in behaviour of "nominally" identical UFG structures produced in different laboratories, makes the comparison of results published in literature troublesome. A variety of possible structures give rise to significant scattering of experimental data on fatigue behaviour published to date [11].

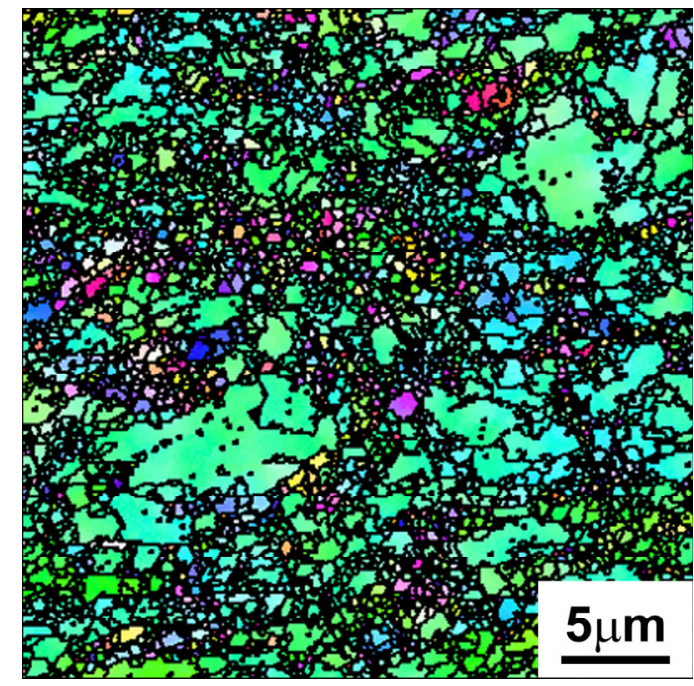

Figure 3a: Grain map of UFG Cu as displayed by EBSD.
Grain Size (diameter)

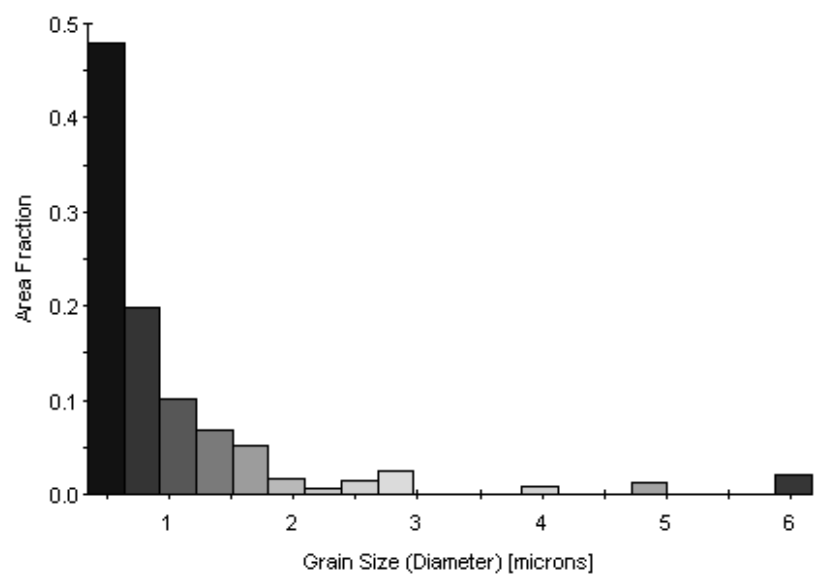

Figure 3b: Analysis of the grain size and grain size distribution.

\section{TENSILE PROPERTIES}

7 he stress-strain diagrams of UFG $\mathrm{Cu}$ prepared by eight passes by route Bc are shown in Fig. 4. The diameter of the gauge length of specimens was $5 \mathrm{~mm}$. Results for two values of the loading rate, 1 and $100 \mathrm{~mm} / \mathrm{s}$, are presented. Surprisingly, there is no strain rate influence in the range of rates applied: both curves are located close each other. The shape of the curves is identical with that observed for UFG Cu prepared by 10 passes by the route C [13]. The curves exhibit a long elastic part at the beginning. The basic tensile properties and modulus of elasticity determined as an average of four measurements are given in Tab.1.

\begin{tabular}{cccc}
\hline Ultimate tensile strength $\sigma_{U T S}$ & Yield stress $\sigma_{0.1}$ & Yield stress $\sigma_{0.2}$ & Modulus of elasticity $E$ \\
{$[\mathrm{MPa}]$} & {$[\mathrm{MPa}]$} & {$[\mathrm{MPa}]$} & {$[\mathrm{GPa}]$} \\
$387 \pm 5$ & $349 \pm 4$ & $375 \pm 4$ & $115 \pm 11$ \\
\hline
\end{tabular}

Table 1: Tensile properties of UFG Cu prepared by ECAP, route $\mathrm{Bc}, 8$ passes.

The ultimate tensile strength after 8 passes is $387 \mathrm{MPa}$. The yield strength $\sigma_{0.2}=375 \mathrm{MPa}$ is very close to the $\sigma_{\text {UTS }}$ and makes $97 \%$ of it. The scatter of the data determined on particular specimens is quite small.

The basic tensile data reported in literature for $\mathrm{Cu}$ processed by ECAP in different laboratories differs considerably, though the microstructure seems to be very similar. For instance, [13] reports $\sigma_{U T S}$ values ranging from 410 to $470 \mathrm{MPa}$, 
for number of passes between 3 and 10, and [14] $443 \mathrm{MPa}$ for 12 passes by the processing route $\mathrm{Bc}$. In [15] the value $\sim 520 \mathrm{MPa}$ for $\mathrm{Cu}$ processed by $12 \mathrm{Bc}$ passes is reported. Generally, during the first passes a rapid increase of strength is observed. However, later on, the strength saturates or even decreases.

From the comparison of tensile diagrams of CG and UFG Cu, Fig. 5, it can be seen that there is a substantial difference in (a) the initial part of the diagram, indicating very high yield strength of UFG Cu and very low one for CG material, and (b) in the tensile strength, being two times higher for the UFG state.

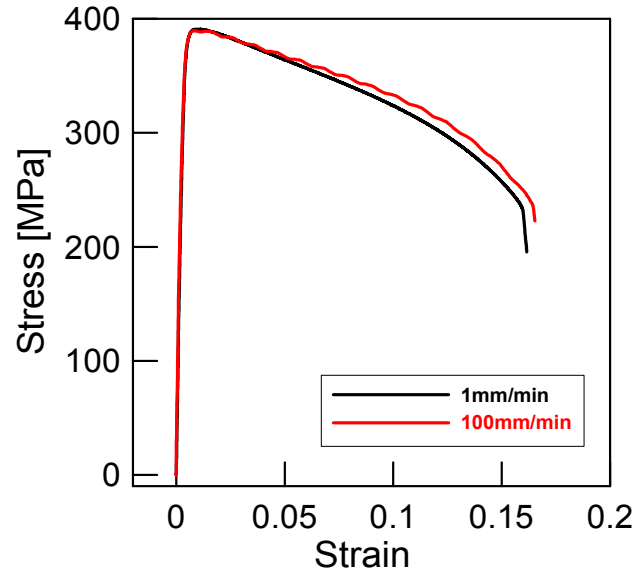

Figure 4: Tensile diagrams of UFG Cu prepared by ECAP, route Bc.

\section{FATIGUE STRENGTH}

$\mathrm{M}$ urphy [1] summarised in a comprehensive review the basic knowledge on copper acquired until the eighties of the last century. The minimum fatigue strength, $\sigma_{c}$, of annealed $\mathrm{Cu}$ at $10^{9}$ cycles to failure is $50 \mathrm{MPa}$; most of data published in literature falls into the interval of 50 to $60 \mathrm{MPa}$. The ultimate tensile strength is in the range of $200-250 \mathrm{MPa}$ for $\mathrm{CG} \mathrm{Cu}$, reflecting the wide range of annealing times, temperatures and the source material. The S-N curve of CG Cu of commercial purity $99.98 \%$ with the average grain size of $70 \mu \mathrm{m}$ can be well described in the interval form $10^{4}$ to $10^{7}$ cycles by Eq. (2):

$$
\sigma_{a}=k N_{f}^{-b}
$$

where $\sigma_{a}$ is the stress amplitude, $N_{f}$ number of cycles to failure, $k=388 \mathrm{MPa}$ and $b=0.107$ [16]. The copper was annealed for $1 \mathrm{hr}$. in vacuum; its $\sigma_{\text {UTS }}$ was $220 \mathrm{MPa}$ and the yield stress, $\sigma_{0.2}$, was $37 \mathrm{MPa}$. The dependence of fatigue strength on the grain size was found to be quite weak. In practice, there is no effect of grain size ranging in the interval 3.4 to $150 \mu \mathrm{m}$ on the fatigue life in the high-cycle fatigue (HCF) region [17]. This behaviour was attributed to easy cross-slip. Later on, the grain size effect was not substantiated even though the grain size was varied from $50 \mu \mathrm{m}$ to $0.5 \mathrm{~mm}$. Generally, it can be summarised that the fatigue life curves expressed both as S-N curves or dependences of number of cycles to failure on the total strain amplitude depend on the grain size of CG Cu insignificantly. This holds especially for fatigue limits based on $10^{7}$ cycles [16].

On the other hand, the Coffin-Manson plot depends strongly on the grain size. The plot is shifted to lower values of plastic strain amplitude, $\sigma_{a p}$, for a given number of cycles to failure with increasing grain size $D$. Experimental data on the number of cycles to failure for plastic strain amplitude of $1 \times 10^{-4}$ indicate a roughly linear increase of $N_{f}$ with $d^{-1 / 2}\left[18^{-}\right.$ 20]. The plastic strain amplitude fatigue limit based on $10^{7}$ cycles was found to be grain size dependent, being $4 \times 10^{-5}$ for fine-grained copper and $2.3 \times 10^{-5}$ for coarse-grained $\mathrm{Cu}$. The explanation of this effect is based on the different conditions for propagation of short cracks, which physically determine the fatigue limit and whose dynamics is a function of obstacles, like grain boundaries.

Copper exhibits strong work hardening, which is a typical effect for most single-phase f.c.c. structures. In fact, the tensile strength of annealed material can be increased by $100 \%$ due to $80 \%$ cold working. Cyclic loading of annealed $\mathrm{Cu}$ results in rapid cyclic hardening followed by a long period of cyclic softening, in a broad temperature interval [21]. Fatigue of 
hardened metals and alloys generally results in cyclic softening; thus, the intensity of this effect depends on the stability of the hardened structure and on the cyclic conditions, i.e. on the level of the stress or strain amplitude [22]. The hardness of $\mathrm{Cu}$, both annealed and cold worked, tends to reach nearly the same value during cycling, provided the fatigue life is of the order of $10^{7}$ cycles. The fatigue strength, irrespective of the fatigue hardening followed by softening, has been shown to increase nearly linearly with the $\sigma_{U T S}$ reached by cold working. This is fulfilled at least up to $40 \%$ of cold work. However, at higher strengths and more severe cold work, a number of anomalous results have been found [1]. Very intensive cold work results often in the fatigue strength, which is even so low as in the case of annealed $\mathrm{Cu}$. The detailed explanation of these results is missing. This is why for engineering applications it is generally recommended that the $\sigma_{U T S}$ of unalloyed $\mathrm{Cu}$ is restricted to less than $325 \mathrm{MPa}$, corresponding to $\sim 30 \%$ cold work.

As a final note, it can be concluded that the fatigue behaviour of $\mathrm{CG} \mathrm{Cu}$ is determined by its dislocation structure developing during cyclic loading and which is a function of external loading parameters. The dislocation activity results in a cyclic slip localisation, which manifests itself by development of a surface relief, consisting of extrusions and intrusions. Just deep intrusions are the critical sites for fatigue crack initiation. In fact, there is a clear relation between the surface relief and the underlying dislocation persistent slip band (PSB) structure. The regions of PSBs are characteristic with higher plastic strain amplitudes than the surrounding interior structure. The structural dimensions, i.e. the characteristic dimensions of the vein structure and PSBs, are generally large compared with the characteristic structural dimensions of UFG $\mathrm{Cu}$. This indicates that the basic knowledge on the cyclic strain localisation and on mechanisms of crack initiation obtained on CG Cu cannot be straightforwardly applied to the grain-refined structures having characteristic dimensions of hundreds of nanometres.

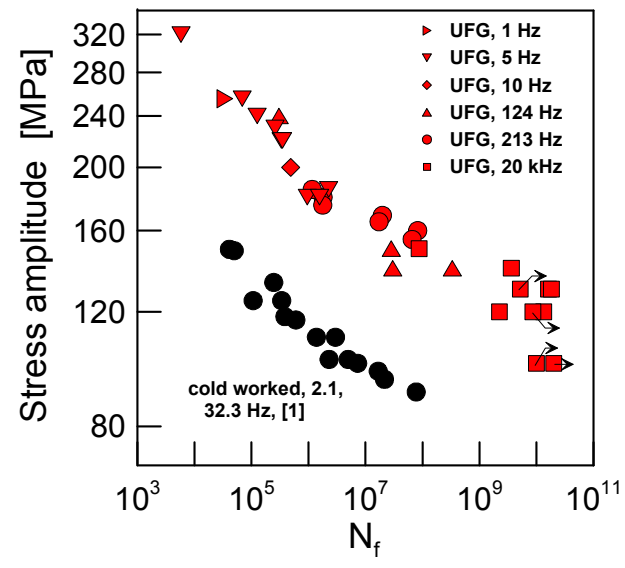

Figure 6: Comparison of S-N data for UFG and cold worked $\mathrm{Cu}$.

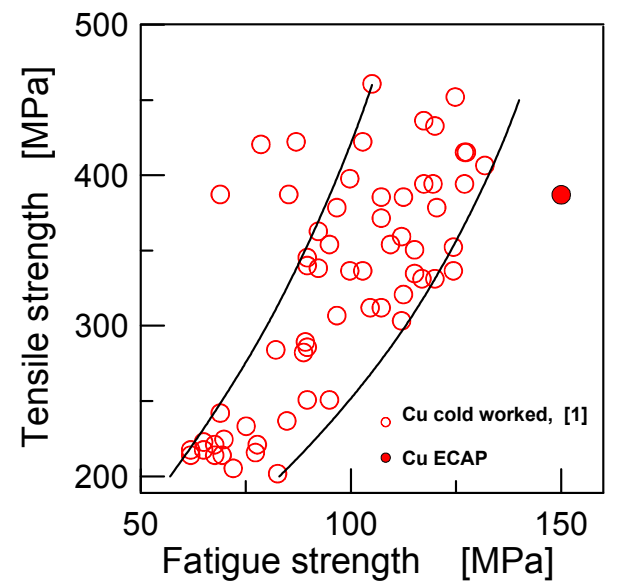

Figure 7: Relation of tensile and fatigue strength for fatigue limit based on $10^{8}$ cycles for cold worked $\mathrm{Cu}$ [1] and UFG Cu.

Let's consider now the UFG structure. The improvement of fatigue performance of $\mathrm{Cu}$ by ECAP processing was experimentally documented in, for example, $[7,11,23-25]$. The S-N curve of $\mathrm{Cu}$ prepared by eight ECAP passes by the route $\mathrm{Bc}$, having the tensile properties given in Tab.1 and the structure shown in Figs. 2 and 3 is shown in Fig. 6. The fatigue loading was performed in load symmetrical cycle in tension-compression. The number of cycles to failure increases continuously with decreasing stress amplitude in very broad interval ranging from low-cycle fatigue (LCF) region up to the gigacycle region. Arrows indicate the run-out specimens. The reasonable description by power law is possible in the first approximation only in the shorter interval, namely from $10^{4}$ to $10^{8}$ cycles by the Eq. (2) with constants $k=584 \mathrm{MPa}$ and $b$ $=-0.078$. The fatigue life of UFG $\mathrm{Cu}$ is substantially higher than that of annealed CG $\mathrm{Cu}$ and also than that of cold worked copper reported by [1]. The S-N curve for UFG material is shifted by a factor of 1.7 towards higher stress amplitudes for a given number of cycles to failure when compared to the cold worked material.

From Fig. 6, it follows that the fatigue limit of UFG Cu based on $10^{8}$ cycles is $150 \mathrm{MPa}$. The $\sigma_{\text {UTS }}$ of this copper is $387 \mathrm{MPa}$. In Fig. 7, which is redrawn from [1], it should be it is shown the relation between the fatigue limit (on the basis of $10^{8}$ cycles) and $\sigma_{U T S}$ for oxygen free cold worked $\mathrm{Cu}$ of purity higher than $99.99 \%$. Increasing tensile strength by cold work increases the fatigue limit. This reasonably holds for $\sigma_{U T S}$ up to $\sim 350 \mathrm{MPa}$. The experimental point corresponding to severely deformed UFG Cu, which is shown in Fig. 7 by the full symbol, lies on the right-hand side of the very broad scatter-band of data. 
A recent overview of the cyclic deformation and fatigue properties of UFG materials evidences that the fatigue behaviour depends strongly on parameters of the ECAP procedure, purity of material and type of fatigue loading [26]. The discussion, interpretation and, in particular, the comparison of results published in literature, requires taking account of all the details of the UFG structures produced in different laboratories and also the external loading parameters and conditions.

In the earliest studies it has been experimentally shown that the lamellar-like elongated type B microstructure shows longer durations under the same stress amplitude than the equiaxial type A [11]. Similar observations were made also on other materials like Ti alloys; however, the available knowledge is not enough to declare that the lamellar-like structures of $\mathrm{UFG} \mathrm{Cu}$ are generally better than equiaxial ones.

The experimental data presented in Fig. 6 give evidence that the UFG structure of Cu can exhibit substantially better fatigue strength expressed in terms of S-N curves than the CG Cu. However, there is also data in literature that indicates quite poor or no improvement of fatigue strength in the HCF region. In [27-29] it is observed the strong enhancement of fatigue life in LCF range but a very weak effect in long-life regime. The fatigue strength of $99.99 \mathrm{wt} \% \mathrm{Cu}$ processed by four passes by route $\mathrm{Bc}$ coincided with that of fully annealed copper for $3 \times 10^{7}$ cycles. This fatigue strength was only slightly enhanced by an increase in the number of ECAP passes and by a decrease in purity. The $\sigma_{U T S}$ of coppers investigated in these studies was high. Fig. 8 compiles the available majority published experimental results up to now on fatigue life of UFG $\mathrm{Cu}$ prepared by ECAP cycled under constant stress amplitudes. S-N data was obtained in different laboratories on different coppers. It is remarkable that the field of the S-N points splits up into two distinct bands. The inspection of the legend in the figure shows that the material purity could be a parameter influencing the HCF strength. The band A covers S-N points for low purity UFG coppers (purity in the range from 99.5 and $99.9 \%$ ), while the band B covers S-N points for high purity UFG coppers (purity in the range from 99.96 to $99.9998 \%$ ). The details of the ECAP process, particularly the type of paths ( $\mathrm{Bc}$ or $\mathrm{C}$ ), seem to have only minor effect on the fatigue performance. The bands merge into one band in the LCF region and obviously diverge in the HCF region. The average stress amplitude corresponding to the $10^{7}$ cycles to failure is around $60 \mathrm{MPa}$ for band $\mathrm{A}$ and around $90 \mathrm{MPa}$ for band $\mathrm{B}$.

The S-N curves of two coppers of substantially different purity tested in a goal-directed research are shown in Fig. 9. Cu was processed by two ECAP routes, namely Bc and C. The fatigue tests were carried out in one laboratory under the same testing conditions. Thus the effect of variances in testing procedures (except of the different specimen shape) is eliminated. It can be seen that the fatigue strength of high purity copper is lower than that of low purity copper. The figure also shows that the ECAP route affects the fatigue strength of pure material. Both the effects, i.e. purity and route, are more pronounced for low stress amplitudes.

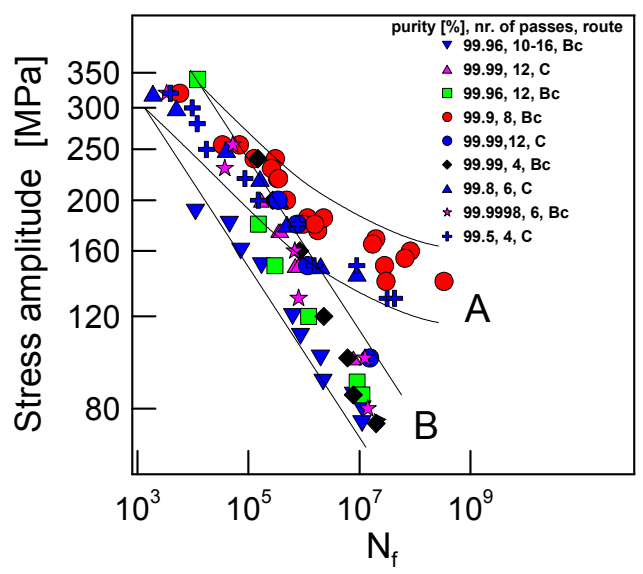

Figure 8: S-N data of UFG Cu of different purity and processed by different routes and number of ECAP passes.

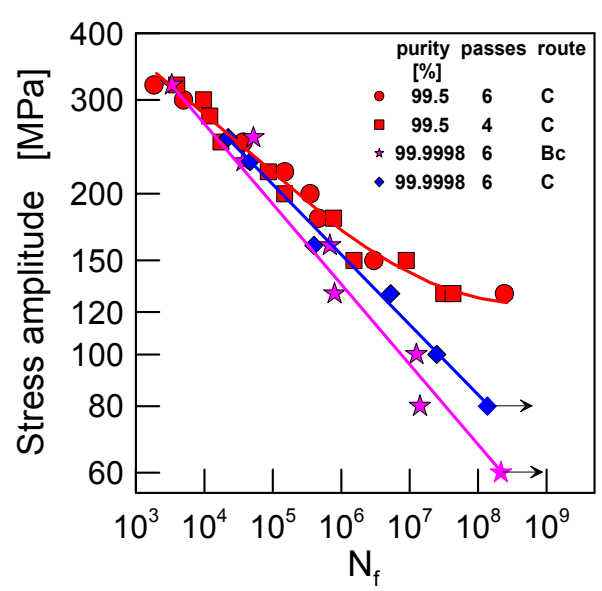

Figure 9: Influence of purity on S-N curves of UFG Cu.

The explanation of the large differences in the fatigue resistance of UFG $\mathrm{Cu}$ in the HCF region shown in Fig. 8 can be sought either in the stability of the microstructure during fatigue loading or in the mechanism of the strain localisation and in the fatigue crack initiation. The stability of UFG structure and crack initiation will be discussed later.

The fatigue lives of UFG Cu are generally higher than those of CG Cu when the comparison is made on the basis of S-N plots. However, just the opposite arises from the comparison on the basis of plastic strain amplitudes. Results of straincontrolled fatigue tests expressed as Coffin-Manson plots show shorter lifetime of UFG than CG Cu [7, 11, 30-32]. The 
effect is more pronounced at higher plastic strain amplitudes. This result seems to be obvious, because the UFG Cu is harder but less ductile than $\mathrm{CG} \mathrm{Cu}$.

\section{FATIGUE CRACK RESISTANCE}

\section{Fatigue crack initiation mechanism}

yclic strain localisation resulting in fatigue crack initiation is an important stage of the fatigue process. In homogeneous materials without defects it represents a substantial part of the fatigue life. As in CG copper, cyclic slip localisation in UFG Cu results in a development of surface relief. Population of cracks associated with extrusions develops during cycling. Because the dimension of slip bands is substantially larger than the grain size of UFG structure, and because they have been often observed to be oriented approximately $45^{\circ}$ from the tension-compression axis [7], we can denote them "shear bands" (SB). Since the early studies of the surface relief development, there are open questions concerning the nature and the mechanism of this phenomenon. The original belief that persistent slip bands (PSBs) with the ladder like dislocation structure might be active in UFG Cu is dubious, since the width of PSBs known from $\mathrm{CG} \mathrm{Cu}$ is larger than the grain size of UFG structure. On the other hand, grain coarsening and development of bimodal structure with large recrystallized grains was also observed, particularly under plastic strain-controlled fatigue loading [26]. Moreover, the dislocation patterns typical for fatigued CG Cu had developed in coarser grains. Ultimately, the relation of formation of SB and grain coarsening is not fully clarified up to now. There is an open question as to whether the process of shear banding is initiated by the local grain coarsening, which leads to the strain localisation destroying the original UFG structure, or the shear localisation takes place abruptly at first and the coarse structure is formed subsequently [32]. Investigation of acoustic emission during cyclic deformation indicates that large-scale shear banding might be an important period of fatigue damage [33].

A characteristic surface relief on fatigued UFG Cu is shown in Fig. 10. The set of parallel slip bands is the result of fatigue loading in the HCF region. The copper is the same as the material on which the S-N curve, Fig. 6, was determined; i.e., material that did not exhibit any grain coarsening under stress-controlled loading. Hence, the local coarsening of UFG structure is not the necessary prerequisite for the formation of these surface reliefs. The length of the cyclic slip bands, see Fig. 10, substantially exceeds the grain size. The cyclic slip bands are formed by extrusions rising over the surface and deep intrusions. The main fatigue crack develops by connection of suitably located intrusions. Cyclic slip bands are also observed in gigacycle fatigue region. An example of a surface relief developed after application of $10^{10}$ cycles is shown in Fig. 11. The density of cyclic slip bands in gigacycle region is very low. The cyclic slip bands produced in gigacycle fatigue region are broad and make an impression of highly deformed local areas incorporating some neighbouring near-by oriented grains. The related intrusions are not deep at all.

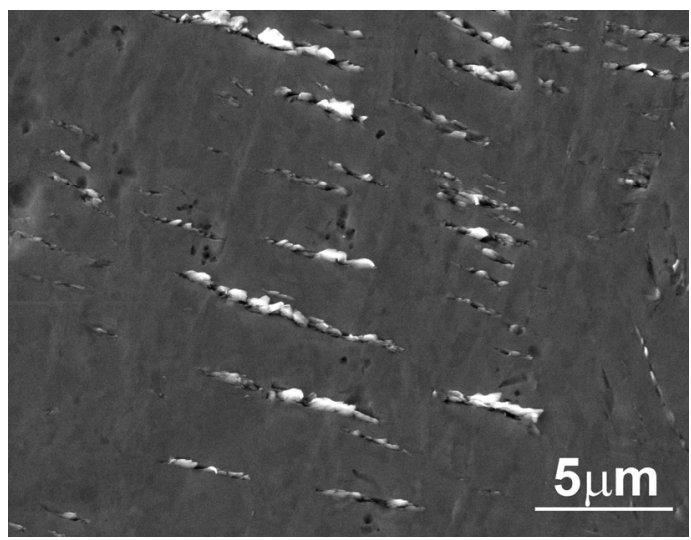

Figure 10: Cyclic slip band on the surface of UFG Cu loaded in HCF region.

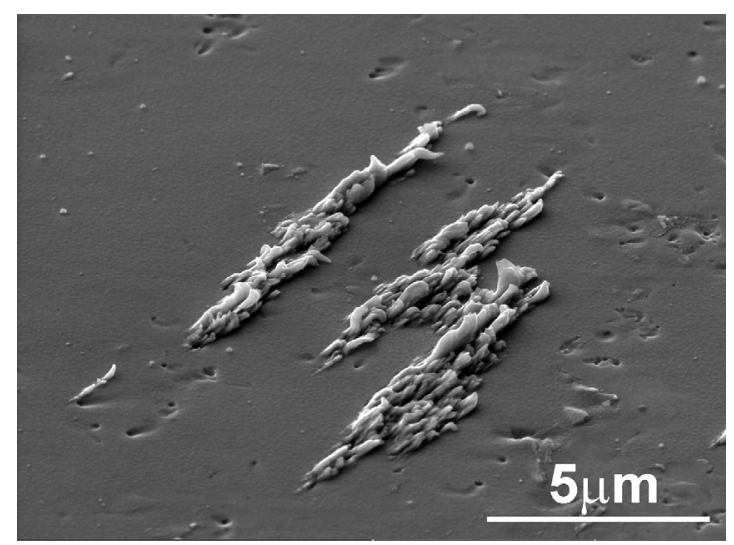

Figure 11: Cyclic slip band on the surface of UFG Cu loaded in gigacycle region.

Based on the present-day state of knowledge it can be concluded that the slip markings in UFG Cu, their shape and main features resemble the slip markings formed in $\mathrm{CG} \mathrm{Cu}$. The local grain coarsening is not a necessary condition for formation of cyclic slip markings and initiation of fatigue cracks. However, the grain coarsening, observed mainly under plastic strain controlled tests, is definitely an important effect that takes place in UFG Cu. The role of the coarsened 
structure in the crack initiation process and the specific mechanism of initiation are not sufficiently understood. Contrary to the $\mathrm{CG} \mathrm{Cu}$, where the specific dislocation structures associated with cyclic slip bands are described thoroughly, there are no similar and conclusive observations on UFG Cu.

\section{Fatigue crack propagation resistance}

The decreasing grain size of metals and alloys results generally in an increase of strength. Improved ultimate tensile strength and yield strength does not mean by itself that the fine-grained materials exhibit also better properties as regards their resistance against the damage by fatigue crack growth. Propagation of long cracks in CG Cu can be well described by linear facture mechanics. There is a good correlation of the crack propagation rate, da/dN, (a is the crack length and $\mathrm{N}$ number of cycles), with the stress intensity factor $\mathrm{K}$. The experimentally determined crack propagation curves for stress symmetrical loading are shown in Fig. 12. The crack rate was in this case determined on sheet central cracked tension specimens manufactured from $\mathrm{Cu}$ of $99.99 \%$ purity. The cycling was conducted under symmetrical load-controlled conditions. It is evident that the grain size influences the crack rate. Cracks in the fine-grained $\mathrm{Cu}$ with the grain size of 70 $\mu \mathrm{m}$ propagate faster than in the coarse grained Cu having the grain size of $1.2 \mathrm{~mm}$ [36]. The experimental points in Fig. 12 can be well approximated by the equation:

$$
d a / d N=A\left(K_{a}^{m}-K_{a t h}^{m}\right)
$$

where $A=1.1 \times 10^{-10}(\mathrm{~mm} / \mathrm{cycle})(\mathrm{MPa} \sqrt{\mathrm{m}})^{-\mathrm{m}}$ and $m=7.0$ for fine grained $\mathrm{Cu}$ and $A=5.0 \times 10^{-11}(\mathrm{~mm} / \mathrm{cycle})(\mathrm{MPa} \sqrt{\mathrm{m}})^{-\mathrm{m}}$ and $m=7.1$ for coarse grained $\mathrm{Cu}$. The threshold value of the stress intensity factor, below which the long cracks do not propagate, is $K_{\text {ath }}=2.1$ and $2.7 \mathrm{MPa} \sqrt{\mathrm{m}}$ for fine-grained and coarse grained $\mathrm{Cu}$, respectively. From this data it is evident that from the point of view of crack propagation the fine-grained $\mathrm{Cu}$ is worse than the coarse-grained one.

There are a plenty of models for propagation of long cracks. They can be divided into three basic groups: 1) models assuming that the plastic deformation in the plastic zone is the determining factor for crack growth, 2) models based on damage in front of the crack tip and 3) models based on energy considerations. The knowledge obtained on the investigation of crack propagation in Cu clearly favours the models based on the crucial role of the cyclic plastic strain at the crack tip.

In $\mathrm{Cu}$ of conventional grain size it has been experimentally shown that a fatigue crack tip is surrounded by a dislocation cell structure in a plastic zone. An example of a dislocation structure adjacent to the long fatigue crack propagating in the Paris law region can be seen in Fig. 13. The fatigue crack was propagating in non-crystallographic manner macroscopically perpendicular to the principal stress. The foils for TEM were prepared in such a way that it was possible to correlate the observed structure with $K_{a}$.

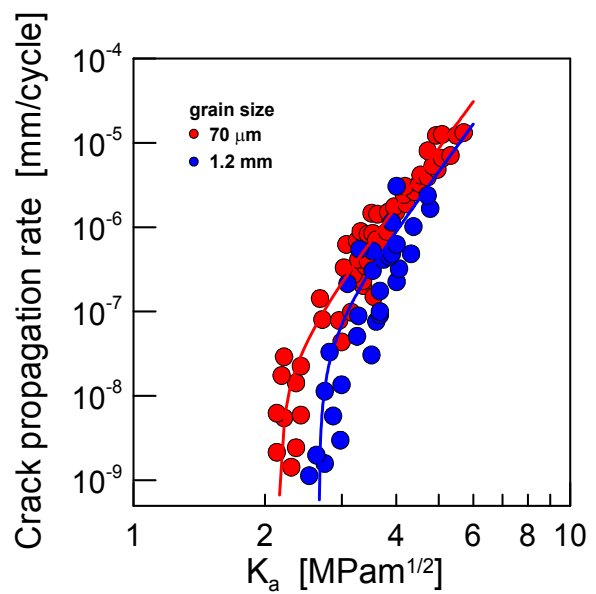

Figure 12: Comparison of crack propagation curves for finegrained and coarse grained $\mathrm{Cu}$.

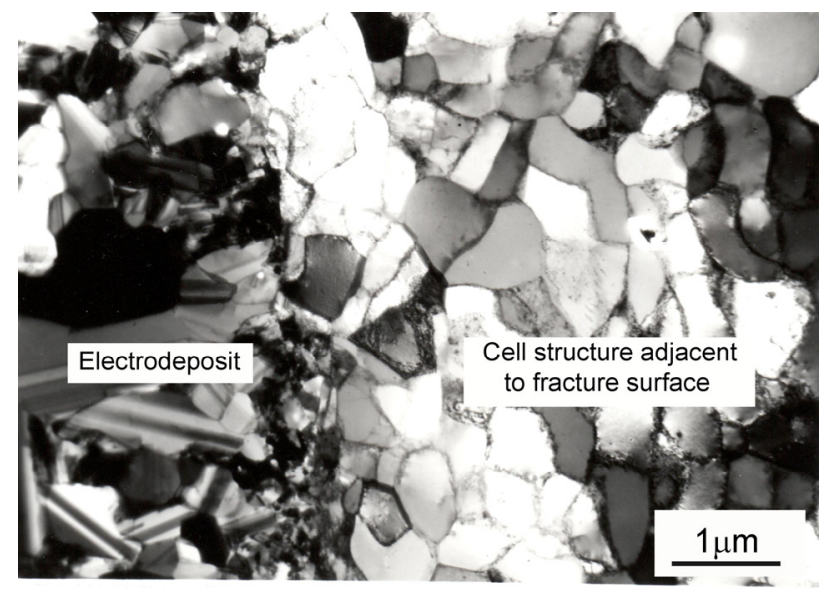

Figure 13: Dislocation cell structure adjacent to fracture surface in conventionally grained $\mathrm{Cu}$.

On the left hand side of Fig. 13 the electrodeposit can be seen. On the right hand side is the well-developed cell structure, which was produced by the cyclic plastic deformation in the plastic zone. The original fatigue fracture surface can be seen in between. An analysis of number of TEM foils indicates that the cell size $d$ is inversely proportional to the $K_{a}$ [34]. 
Based on the observation of the dislocation structures near the crack tip in $\mathrm{Cu}$, the following considerations can be made. At high crack growth rates and relatively small grain size the "fracture mechanical" plastic zone consisting of cell structure is large compared to the length of PSBs, which develop before the propagating crack tip. The plastic strain amplitude at the crack tip controls the crack growth process. However, for low crack growth rates and coarse-grained Cu the ratio of the length of PSBs terminating on the grain boundaries to the cell zone size increases. Some observations show that the cell zone can vanish completely in the near threshold crack growth conditions. The decisive majority of the cyclic plastic strain is concentrated in the PSBs. This type of plastic zone is different from the fracture mechanical zone, which develops at loading with high $K_{a}$. It is obvious that this effect and effect of grain size can influence the crack growth rate. Now, UFG Cu produced by ECAP has a typical grain size (cell size) of about $300 \mathrm{~nm}$. This is comparable to the smallest cells observed at the tip of a fatigue crack propagating at the conditions characterized by $K_{a} \sim 10 \mathrm{MPa} \sqrt{\mathrm{m}}$ [35]. From this point of view, the crack propagation resistance of UFG and CG copper in this region should be similar; strong differences, however, can be expected in the threshold region. Here the stability of UFG structure would play a decisive role. A study of the crack propagation in UFG Cu prepared by high pressure torsion is reported in [36]. The crack propagation was studied on very thin specimens loaded in gigacycle region at ultrasonic frequency. The researchers observed a very intensive grain coarsening in the vicinity of the fatigue crack in $\mathrm{Cu}$ of high purity. The retardation of the crack growth was reported and explained just by this effect.

The resistance to the propagation of long cracks in UFG copper determined experimentally on round compact tension specimens is presented in Fig. 14. The form of the plot is the traditional $\log -\log \left(d a / d N ; \Delta K=K_{\max }-K_{\min }\right)$ diagram.

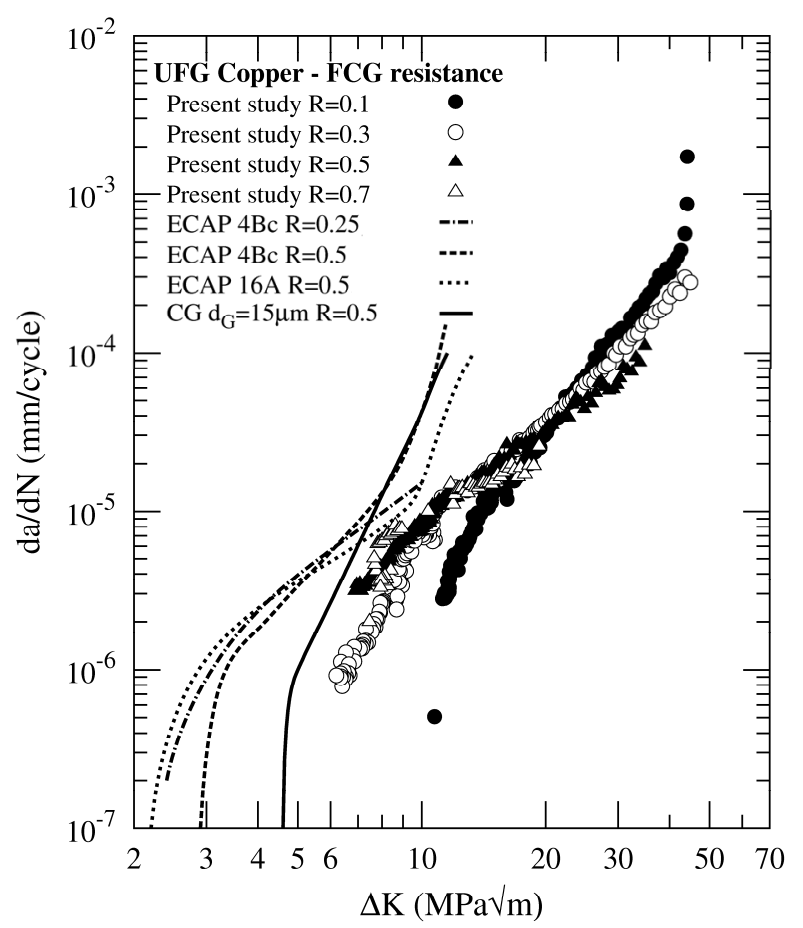

Figure 14: Fatigue crack growth curves for 8-ECAPed UFG copper.

Different load ratios $\mathrm{R}=K_{\min } / K_{\max }$ were used in experiments. Other data from the literature are plotted for comparison. In particular, these last are: i) fatigue crack growth (FCG) curve at $R=0.25$ of pure UFG Cu ECAPed by 4Bc passes with grain size $d_{G}=270 \mathrm{~nm}$ [37]; ii) FCG curve at $R=0.5$ of UFG Cu 4Bc passes and $d_{G}=300 \mathrm{~nm}$ [38]; iii) FCG curve at $R=$ 0.5 of UFG Cu 16A ECAP with $d_{G}=300 \mathrm{~nm}$ [38]; iv) FCG plot at $\mathrm{R}=0.5$ of CG copper with $d_{G}=15 \mu \mathrm{m}$ [1].

From the analysis of data it follows that - as for the conventional metals - points in stage II of propagation, can be fitted by the classical Paris law:

$$
d a / d N=C(\Delta K)^{m}
$$

with $C$ and $m$ coefficients depending on $R$-ratio: $C=7.72 \times 10^{-10}, 3.75 \times 10^{-8}, 1.10 \times 10^{-7}, 4.10 \times 10^{-7}$ and $m=3.54,2.32,1.90$, 1.36 at $R=0.1,0.3,0.5,0.7$ respectively. 
These results on low-purity UFG copper evidence a better resistance to the crack propagation with respect to other UFG structures taken into consideration for comparison. Even, in stage II the present UFG Cu shows higher FCG resistance than the CG counterpart.

On the other hand, the threshold regime and values of "extrapolated" threshold stress intensity factor $\Delta K_{t h}$ (details of the procedure are given in $[39,40]$ ) show that (i) the load ratio influences the threshold FCG regime, since higher is $R$, lower is $\Delta K_{t h}$, as one can evince from Fig. 15, (ii) that the threshold $K$ is higher than values found in literature for the same class of UFG copper, and (iii) if compared with the FCG behaviour of annealed and cold worked conventional Cu alloys, the present UFG microstructure shows higher threshold resistance for R-ratios 0.1 and 0.3 , and lower when R-ratio increases, see Fig. 15; this result is partially in contrast with other investigations on UFG structures with different purity levels.

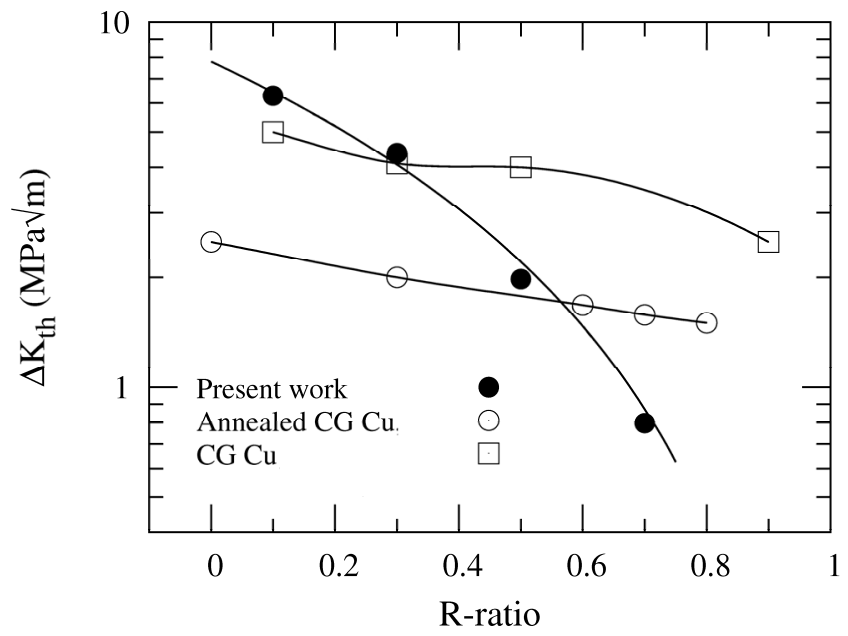

Figure 15: Threshold stress intensity factors of 8-ECAPed UFG copper.

In order to explain the relatively high crack propagation resistance of the present UFG copper, its fatigue resistance was analyzed. As previously showed, the higher fatigue resistance has been justified demonstrating the stability of the bulk microstructure during cycling, due to the stable dislocations structure and to the presence of impurities. The grain structure within the plastic zone around the cracks was shown to differ from outside of the plastic zone: the grains were found markedly elongated, but their size was preserved. Also, in comparison with the CG structure, a small grain size can potentially result in more homogeneous deformation, which can retard crack nucleation by reducing stress concentrations and ultimately raise the fatigue limit of the UFG structure. This has been demonstrated by other studies on ECAPed copper structures on low and high cycle fatigue [41,42]. Thus, the interaction between a propagating crack and the GBs structure can produce retardation in the growth rate [43]. This phenomenon has been already noticed and theoretical models on the crack-boundaries interaction developed, with the support of experimental evidences [44,45]. The study of crack propagation in UFG Cu loaded at rotating bending and based on the observation of replicas, brought an evidence of crack growth retardation due to fine-grained structure [46]. The structurally induced retardation, however, was observed only for lowest loading amplitudes and in the region of very small crack propagation rates. The available knowledge on the propagation of fatigue cracks in UFG Cu is not sufficient for serious conclusions concerning the threshold values and details of the crack growth mechanism. It seems that the topological factors can be critical in the FCG behaviour of UFG metals, if one considers the huge number of GBs generated by the grain refinement process.

\section{CONSIDERATIONS ON STABILITY AND IMPURITIES OF UFG STRUCTURES}

$\mathrm{S}$ tability of a severely deformed structure is of utmost importance from the point of view of its fatigue properties [47]. The critical issue of a successful application of UFG materials is the long-term stability of microstructure, in services where cyclic loads, often with mean stress, are frequent. Also loading at elevated temperatures can be expected in engineering practice. Despite this, knowledge of the stability of UFG structure under dynamic and temperature loading is quite scarce. There are open questions concerning the mechanisms of the grain coarsening both under cyclic loading and temperature exposition. 


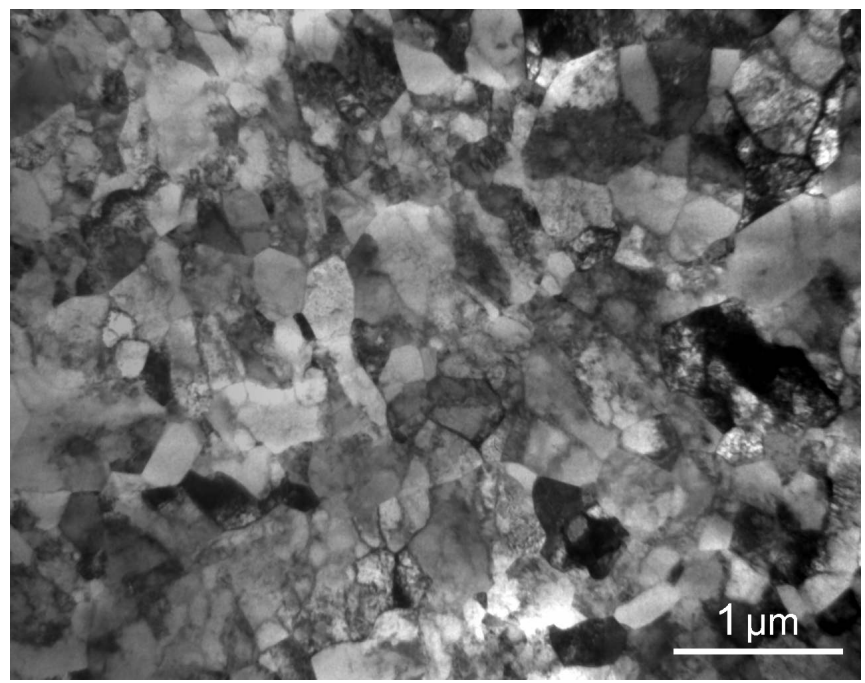

Figure 16: Microstructure after $10^{10}$ cycles.

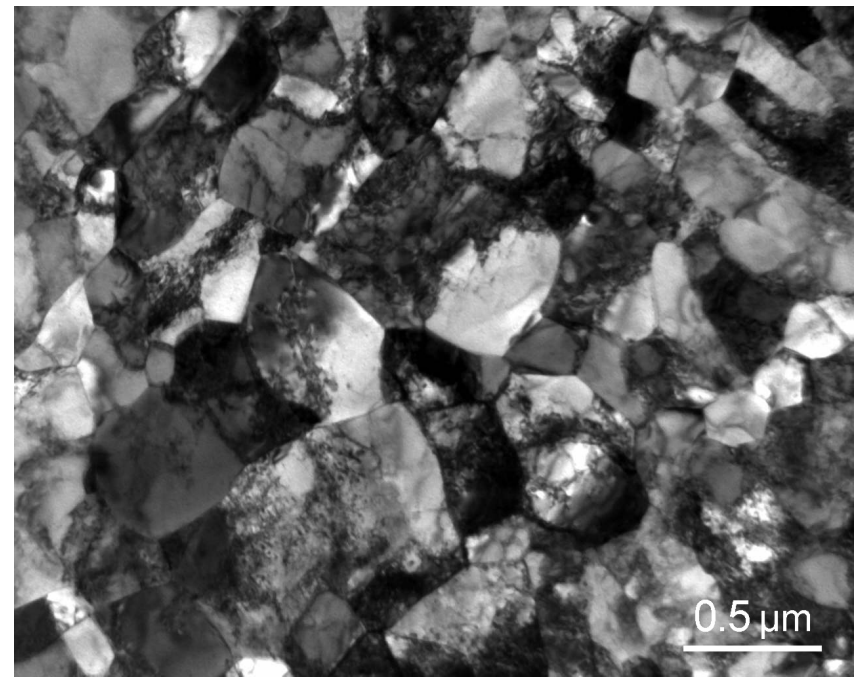

Figure 17: Microstructure after fatigue loading exhibiting "shaken down" features.

ECAP results in structures that are in metastable state. There is a natural tendency for recovery and recrystallization driven by a decrease of high stored energy. Hence, substantial changes of microstructure can be expected in course of fatigue. Really, the total strain-controlled tests of UFG Cu showed a marked heterogeneity of dislocation structure after fatigue loading, which resulted in failure of specimens after $10^{4}$ cycles. Three types of structures were described: a) subgrain/cell structure, which resembles the well-known structure from LCF tests of CG Cu; b) a fine-grained lamellar structure as observed in $\mathrm{Cu}$ after ECAP; c) areas with large grains with primary dipolar dislocation walls. The first two types of structure were found to be the majority. The intensity of grain coarsening decreases with decreasing plastic strain amplitude in a strain-controlled test [48]. Pronounced local coarsening of microstructure when compared to the initial state was found after cycling with $\varepsilon_{a p}=1 \times 10^{-4}$. Observation by TEM revealed very pronounced fatigue-induced grain coarsening that occurred in some areas by dynamic recrystallization. This process takes place at a low homologous temperature of about 0.2 of the melting temperature [26]. The structure is described as "bimodal". Dislocation patterns, characteristic for fatigue deformation of CG Cu, have developed in the coarser recrystallized grains. It is believed that this grain coarsening is closely related to the strain localisation [49]. On the other hand, it is interesting to note that after fatigue at the plastic strain amplitude of $10^{-3}$ the grain coarsening was not observed.

Examination of the microstructure of failed specimens, which were used for the determination of the S-N curve of UFG $\mathrm{Cu}$ in Fig. 6, brought no evidence of structural changes, even for the highest stress amplitudes in LCF region. The average grain size is $300 \mathrm{~nm}$ with the scatter usual for determination of the grain size in as ECAPed material. Cyclic softening is a characteristic feature for the whole lifetime. This means that the cyclic softening is not directly related to the grain coarsening. This finding is in agreement with the observations in [30], where is noticed that the decrease in hardness of UFG Cu after fatigue does not scale with the cell size $d_{\text {cell }}$ according to a well-known relationship between the saturation stress, $\sigma_{a, \text { sat }}$, and $d_{\text {cell }}$ of the type $\sigma_{a \text { sat }} \sim\left(d_{\text {cell }}\right)^{-1 / 2}$. This suggests that the mechanism of softening is related to the decrease of defect density and changes of boundary misorientation rather than to the gain size.

The highest number of cycles applied by the determination of the S-N curve, Fig. 6, was of the order of $10^{10}$ and was reached by ultrasonic loading at $20 \mathrm{kHz}$. Fig. 16 shows the TEM image of a structure of a specimen, which failed after 1.34 x $10^{10}$ cycles. Comparison with Fig. 2 implies no grain size changes after stress-controlled loading in gigacycle region. The characteristic cyclic stress-strain response in a very high-cycle region is continuous cyclic hardening; i.e., qualitatively different from that under cycling with high stress amplitudes.

Detailed analysis of many TEM micrographs tempts to believe that the fatigue loading with constant stress amplitude in the interval form 320 to $120 \mathrm{MPa}$, Fig. 6, does not result in the grain growth. The only observed structural change is a weak tendency to develop more "shaken down" dislocation structures [24]. An example is presented in Fig. 17.

In the case of UFG Cu significant differences in the structure stability were observed depending on the mode of fatigue testing. Generally, low stability of UFG structure was reported for plastic strain-controlled tests. The characteristic effect is formation of bimodal structure and shear banding [25]. Due to the obvious high sensitivity of fatigue behaviour of UFG 
$\mathrm{Cu}$ to internal and external parameters, it is difficult to draw reliable conclusions from the comparison of literature data, which cover differently produced materials, different purity and different testing conditions. This is why on UFG Cu, on which the S-N curve in Fig. 6 was determined, the plastic strain controlled tests were conducted. An example of dislocation structures of material from a failed specimen loaded with $\varepsilon_{a p}=0.1 \%$ is shown in Fig. 18 . A well-developed bimodal microstructure consisting of areas with original fine-grained structure and large recrystallized grains with dislocation structure in their interior can be seen. This observation is in full agreement with results published in [26,49]. For comparison, the characteristic dislocation structure of a specimen loaded with the constant stress amplitude of $340 \mathrm{MPa}$ is shown in Fig. 19. This structure does not exhibit any traces of bimodal structure, though the stress amplitude used is equal to the maximum value of the stress amplitude in the plastic strain amplitude-controlled test with $\varepsilon_{a p}=1 \mathrm{x} 10^{-3}$. This means that the absolute value of the stress amplitude cannot be the reason for the substantially different stability of UFG structure under both types of tests. Also, the details of ECAP procedure are excluded. The tests were run on the same material. Also the frequency of loading in both tests was similar. The differences in the cumulative plastic strain amplitude in both tests were also not substantially different. The only difference between the two test modes, which can cause the different microstructure, seems to be the stress-strain response at the very beginning of the tests. There is relatively low plastic strain amplitude at the beginning of the stress-controlled test when compared to the strain-controlled test. It can be supposed that just the cycling with low strain amplitude at the beginning of the stress-controlled test can prevent the substantial changes of microstructure due to subsequent loading with increasing $\varepsilon_{a p}$. However, this idea is based on a small number of tests; further experimental study is necessary to support this opinion.

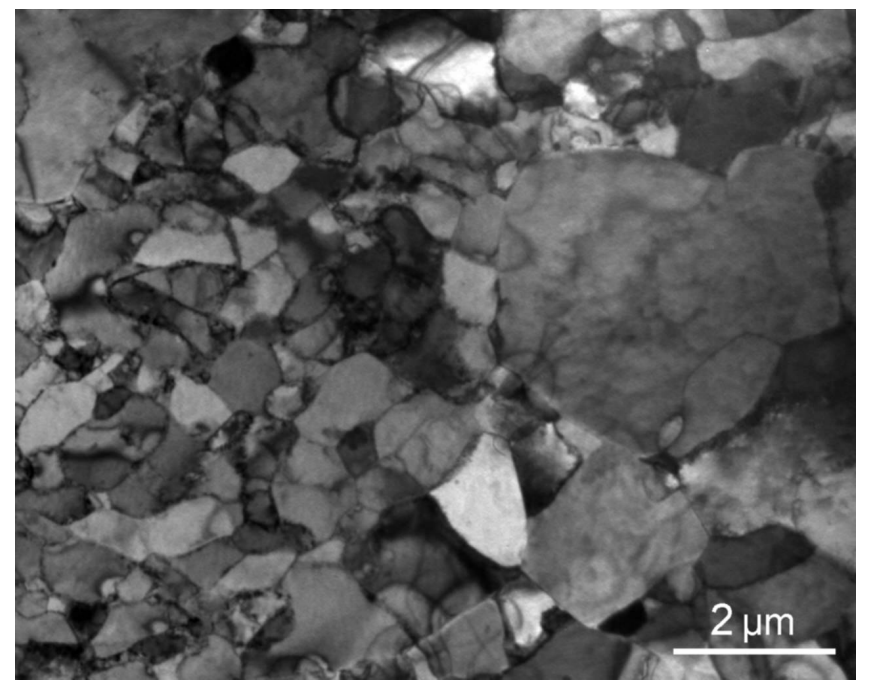

Figure 18: Bi-modal dislocation structure after constant plastic strain amplitude loading.

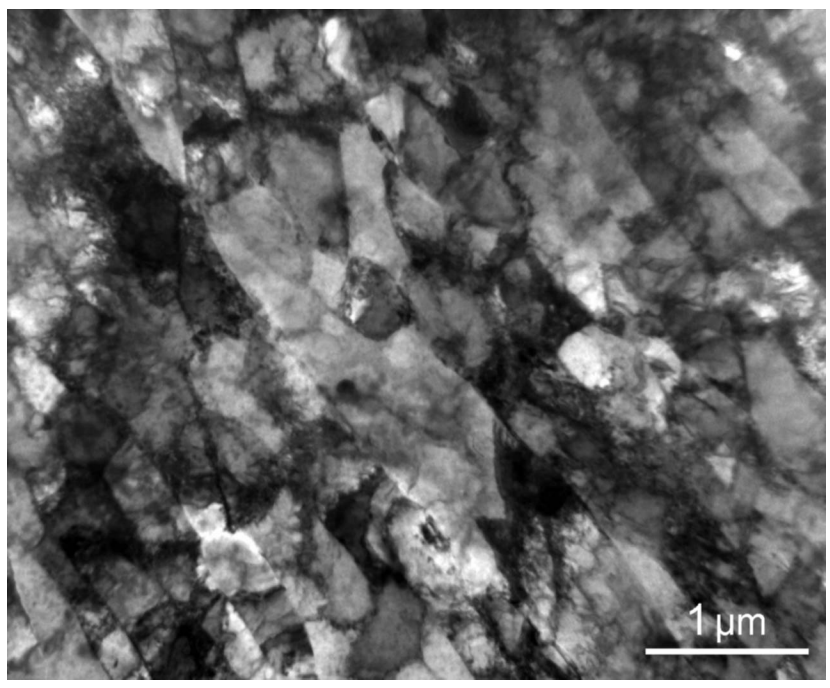

Figure 19: Dislocation structure after constant stress amplitude loading, $\sigma_{a}=340 \mathrm{MPa}$.

The up to now knowledge on the stability of UFG structure of $\mathrm{Cu}$ under cyclic loading is not sufficient to draw definite conclusions. On the other hand, it seems to be proven that the enhanced ductility and stable microstructure are major facts that enhance the fatigue properties [32]. If the structural stability is low (due to internal material parameters or type of loading), the fatigue properties of UFG Cu are substantially reduced.

\section{CONCLUSIONS}

$\mathrm{F}$ atigue performance of $\mathrm{Cu}$ can be substantially improved by severe plastic deformation. The fatigue strength corresponding to $10^{8}$ cycles to failure can reach up to $150 \mathrm{MPa}$ and $120 \mathrm{MPa}$ for $10^{10}$ cycles, provided that the loading is performed in stress-control and the UFG microstructure remains stable. The stability depends on material, i.e. on the details of microstructure produced by SPD. On the other hand, if the fatigue loading is performed in the plastic strain-controlled regime, the UFG structure is more prone to the grain coarsening, and the fatigue life for the same plastic strain amplitude is substantially shorter than that of CG material. 
The fatigue cracks in UFG structure initiate at cyclic slip bands, which are observed under all types of loading and from the LCF to gigacycle region. With decreasing severity of cyclic loading their density decreases and their appearance slightly changes. However, the details of the fatigue crack initiation mechanism are not sufficiently known; particularly, no specific dislocations structures were found beneath the slip bands. The up-to now state of knowledge favours the role of the grain boundary sliding in the crack initiation process.

The available data on fatigue crack propagation resistance are somewhat contradictory. Both a higher and lower sensitivity to the crack growth in the threshold region (when compared to CG Cu) was found. The mechanism of the crack propagation and its relation to the microstructure and its changes should be the topic of further goal-directed investigations.

\section{ACKNOWLEDGMENT}

he Czech Science Foundation under contract 108/10/2001 financially supported this work. This support is gratefully acknowledged.

\section{REFERENCES}

[1] M.C. Murphy, Fatigue of Engng. Mater and Struct., 4 (1981) 199.

[2] G. Saada, Mat. Sci. Eng. A.,400-401 (2005) 146.

[3] V. M. Segal, Mat. Sci. Eng. A., 197 (1995) 157.

[4] R. Z.Valiev, T.G. Langdon, Prog Mater Sci., 51 (2006) 881.

[5] J.T. Wang, et al. (Eds.), Nanomaterials by severe plastic deformation: NanoSPD5. TTP Publications LTD, Switzerland, (2011).

[6] A. Vinogradov, Y. Kaneko, K. Kitagawa, S. Hashimoto, V. Stolyarov, R. Valiev, Scripta Mater., 36 (1997) 1345.

[7] S. R. Agnew, A. Yu. Vinogradov, , S. Hashimoto, J. R. Weertman, J. Electronic Mater., 28 (1999) 1038.

[8] R.Z.Valiev, R.K. Islamgaliev, I.V. Alexandrov, Prog. Mater. Sci., 45 (2000) 103.

[9] Y. T. Zhu, T. G. Langdon, JOM, (2004) 58.

[10] B. Mingler, H.P. Karnthaler, M. Zehetbauer, R.Z. Valiev, Mat. Sci. Eng. A, 319-321 (2001) 242.

[11] A. Vinogradov, S.Hashimoto, Mater. Trans.,42 (2001) 74.

[12] A. J. Wilkinson, P. B. Hirch, Micron, 28 (1997) 279.

[13] M. Besterci, T. Kvackaj, L. Kovác, K. Sulleiová, Kovove Mater., 44 (2006) 101.

[14] M. Goto, S. Z. Han, S. S. Kim, Y. Ando, N. Kwagoishi, Scripta Mat., 60 (2009) 729.

[15] A. Vinogradov, S. Hashimoto, V. Patlan, K. Kitagawa, Mat. Sci. Eng. A., 319 (2001) 862.

[16] P. Lukáš, L. Kunz, Mat. Sci. Eng., 85 (1987) 67.

[17] A. W. Thompson, W. A. Backofen, Acta Met., 19 (1971) 597.

[18] P. Lukáš, M.Klesnil, Mat. Sci. Eng., 11 (1973) 345.

[19] J. Polák, M.Klesnil, Mat. Sci. Eng., 63 (1984) 189.

[20] V. T. Kuokkala, P. Kettunen, Fat. Fract. Eng. Mater. and Struct., 8 (1985) 277.

[21] P. Lukáš, L. Kunz, Mat. Sci. Eng. A., 103 (1988) 233.

[22] M. Klesnil, P. Lukáš, Fatigue of metallic materials, Academia/Elsevier, Prague, Czech Republic (1992).

[23] H. W. Höppel, R. Z. Valiev, Z. Metallkd., 93 (2002) 641.

[24] L. Kunz, P. Lukáš, M. Svoboda, Mat. Sci. Eng. A., 424 (2006) 97.

[25] H. W. Höppel, H. Mughrabi, A. Vinogradov, In: Bulk Nanostructured materials, Zehetbauer, M. et al. (Eds.), WileyVCH Verlag, Weinheim (2009) 481.

[26] H. Mughrabi, H. W. Höppel, Int. J. Fatigue, 32 (2010) 1413.

[27] S. Z. Han, M. Goto, Ch. Lim, S.H. Kim, S. Kim, J of Alloys and Comp., 434-435 (2007) 304.

[28] S. Z. Han, M. Goto, Ch. Lim, S.H. Kim, S. Kim, J of Alloys and Comp., 483 (2009) 159.

[29] M. Goto, S. Z. Han, T. Yakushiji, S. S. Kim, C. Y. Lim, Int. J. Fatigue, 30 (2008) 1333.

[30] S. R. Agnew, J. R. Weertman, Mat. Sci. Eng. A., 244 (1988) 145.

[31] H. W. Höppel, M. Kautz, C. Xu, M. Murashkin, T. G. Langdon, R. Z. Valiev, H. Mughrabi, Int. J. Fatigue, 28 (2006) 1001. 
[32] H. Mughrabi, H. W. Höppel, M. Kautz, In: Ultrafine grained materials IV, Zhu, Y. T. et al. (Eds.), TMS, (2006) 47.

[33] A. Vinogradov, V. Patlan, S. Hashimoto, K. Kitagawa, Phil. Mag., 82 (2002) 317.

[34] P. Lukáš, L. Kunz, Acta Technica CSAV, 4 (1986) 460.

[35] P. Lukáš, L. Kunz, Mat. Sci. Eng., 74 (1985) L1.

[36]J. Horky, G. Khatibi, B. Weiss, M. J. Zehetbauer, J All Comp., 509S (2011) 323.

[37] P. Cavaliere, Int J Fatigue, 31(10) (2009) 1476.

[38] A. Vinogradov, J Mater Sci., 42 (2007) 1797.

[39] L. Collini, Proc Eng., 2(1) (2010) 2065.

[40] L. Collini, Eng Fract Mech., 77 (2010) 1001.

[41] T. Hanlon, E. D. Tabachnikova, S. Suresh, Int J Fatigue, 27 (2005) 1147.

[42] Y. Estrin, A. Vinogradov, Int J Fatigue, 32(6) (2010) 898.

[43] A. K. Vasudevan, K. Sadananda, K. Rajan, Int J Fatigue, 19(1) (1991) S151.

[44] C. Holzapfel, W. Schäf, M. Marx, H. Vehoff, F. Mücklich, Scripta Mater., 56 (2007) 697.

[45] T. Zhai, A. J. Wilkinson, J. W. Martin, Acta Mater., 48 (2000) 4917.

[46] M. Goto, Y. Ando, S. Z. Han, S.S. Kim, N. Kawagoishi, K. Euh, Eng Fract Mech, 77 (2010) 1914.

[47] Ch. C.F. Kwan, Z. Wang, Mat. Sci. Forum, 683 (2011) 55.

[48] H. W. Höppel, Z. M. Zhou, H. Mughrabi, R. Z. Valiev, Phil. Mag., 82 (2002) 1781.

[49] H. Mughrabi, H. W. Höppel, In: Mat. Res. Soc. Symp. Proc. Farkas, D. et al. (Eds.), Mater. Res. Soc. Warrendale Penn. (2001) 634. 